\title{
Modelling the spatial distribution of snow water equivalent at the catchment scale taking into account changes in snow covered area
}

\section{T. Skaugen and F. Randen}

Norwegian Water Resources and energy Directorate, P.O. Box 5091, Maj. 0301 Oslo, Norway

Received: 15 December 2011 - Accepted: 16 December 2011

- Published: 22 December 2011

Correspondence to: T. Skaugen (ths@nve.no)

Published by Copernicus Publications on behalf of the European Geosciences Union.

Modelling the spatial distribution of snow water equivalent

T. Skaugen and

F. Randen

\section{Title Page}

\section{Abstract}

Conclusions

Tables

14

4

Back

Full Screen / Esc

Printer-friendly Version 
A successful modelling of the snow reservoir is necessary for water resources assessments and the mitigation of spring flood hazards. A good estimate of the spatial probability density function (PDF) of snow water equivalent (SWE) is important for ob5 taining estimates of the snow reservoir, but also for modelling the changes in snow covered area (SCA), which is crucial for the runoff dynamics in spring. In a previous paper the PDF of SWE was modelled as a sum of temporally correlated gamma distributed variables. This methodology was constrained to estimate the PDF of SWE for snow covered areas only. In order to model the PDF of SWE for a catchment, we need to take into account the change in snow coverage and provide the spatial moments of SWE for both snow covered areas and for the catchment as a whole. The spatial PDF of accumulated SWE is, also in this study, modelled as a sum of correlated gamma distributed variables. After accumulation and melting events the changes in the spatial moments are weighted by changes in SCA. The spatial variance of accumulated SWE 15 is, after both accumulation- and melting events, evaluated by use of the covariance matrix. For accumulation events there are only positive elements in the covariance matrix, whereas for melting events, there are both positive and negative elements. The negative elements dictate that the correlation between melt and SWE is negative. The negative contributions become dominant only after some time into the melting season so at the onset of the melting season, the spatial variance thus continues to increase, for later to decrease. This behaviour is consistent with observations and called the "hysteretic" effect by some authors. The parameters for the snow distribution model can be estimated from observed historical precipitation data which reduces by one the number of parameters to be calibrated in a hydrological model. Results from the model are in good agreement with observed spatial moments of SWE and SCA and found to provide better estimates of the spatial variability than the current model for snow distribution used in the HBV model, the hydrological model used for flood forecasting

\section{Modelling the spatial distribution of snow water equivalent}

T. Skaugen and F. Randen

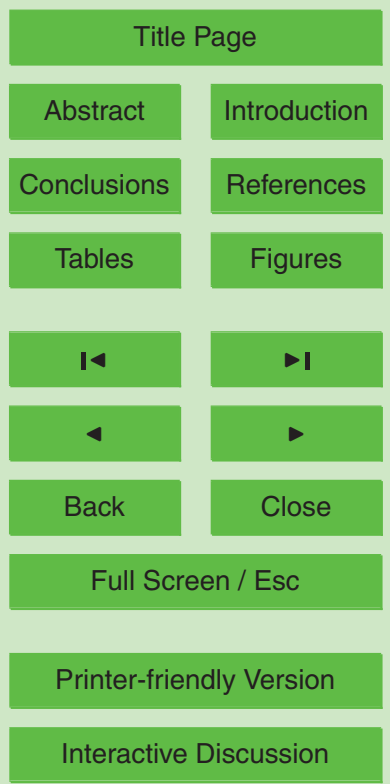


in Norway. When implemented in the HBV model, simulations show that the precision in predicting runoff is maintained although there is one parameter less to calibrate.

\section{Introduction}

Snow is an important hydrological parameter in the northern hemisphere and quantify5 ing the snow reservoir is necessary for water resources assessment and for mitigating the potential hazard of the spring flood. In order to successfully simulate the temporal evolution of the snow reservoir, snow melt and the snow covered area (SCA), the spatial probability density function (PDF) of snow water equivalent (SWE) plays a key role (Luce and Tarboton, 2004; Essery and Pomeroy, 2004; Luce et al., 1999; Liston, 1999; 10 Buttle and McDonnel, 1987). Furthermore, the spatial PDF of SWE is known to vary throughout the snow season. This was observed by Pomeroy et al. (2004) during the melt period and through the entire snow season by Alfnes et al. (2004). The algorithms used to describe the spatial PDF of SWE in hydrological models thus have to take this feature into account.

15 The spatial PDF of SWE often serves as the basis for modelling SCA. The temporal development of SCA is important in hydrology and in land surface schemes in atmospheric models. The dynamics of runoff is affected by changes of the area generating melt water and flux accounting must be carried out separately for snow-free and snowcovered fractions of a grid in a land- surface scheme (Essery and Pomeroy, 2004; Liston, 1999). The snow cover depletion curve (SDC) can be derived from the spatial PDF of SWE and describes the relationship between SCA and spatially averaged SWE (Martinec et al., 1994; Luce et al., 1999; Luce and Tarboton, 2004). Luce et al. (1999) derived the SDC from integrating a generic PDF of SWE which shifts to the left as melting proceeds. Essery and Pomeroy (2004) assumed a log-normal distribution of SWE when they showed how the sign of the correlation between melt and SWE influences the SDC. Shamir and Georgakakos (2007) discussed the high inter-annual variability

\section{HESSD}

$8,11485-11518,2011$

Modelling the spatial distribution of snow water equivalent

T. Skaugen and F. Randen

Title Page

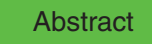

Introduction

Conclusions

Tables

References

Figures

14

4

Back

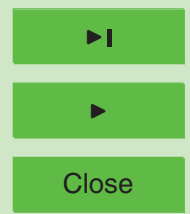

Full Screen / Esc

Printer-friendly Version

Interactive Discussion 
in SDC for single catchments which translates to inter-annual variability in spatial PDF of SWE.

A highly relevant parameter that has to be taken into account when modelling snowmelt and the evolution of snow-free areas, is the correlation between SWE and 5 melt. Essery and Pomeroy (2004) show that, given a PDF for SWE, the relation between changes in SCA and mean SWE (the SDC) varies according to the sign and magnitude of the correlation between melt and SWE. There has been some debate in the literature regarding the nature of this correlation and Faria et al. (2000) found that the spatial distribution of daily melt was negatively correlated to the distribution of 10 SWE within a boreal forest stand. Pomeroy et al. (2001), however found no spatial covariance between melt energy and SWE in dense mature spruce forest, although this does not directly describe the correlation between melt rate and SWE. Furthermore, Pomeroy et al. (2004) found negative correlation at small scales $(<100 \mathrm{~m})$, and medium scales $(<2000 \mathrm{~m})$ and even positive correlations at the catchment scale $(<200 \mathrm{~km})$. 15 In addition to these non-conclusive findings, both Pomeroy et al. (2004) and Skaugen (2007) reported that the relationship between spatial mean and variance of SWE is not monotonous throughout the accumulation and melting season. At the very beginning of the melting season the spatial mean decreased whereas the variance increased slightly then later declined with the mean. This behaviour is also seen in studies in the 20 Swiss Alps, where the spatial mean of SWE plotted against the spatial standard deviation shows that their relation is not one-to-one (Egli and Jonas, 2010; Egli et al., 2011). In the Swiss studies, this phenomenon is called hysteresis, suggesting that predicting the variance requires the history of the mean and not just the mean

In Skaugen (2007) a method for estimating a temporally varying spatial PDF of SWE 25 was introduced. This distribution has the ability to reproduce the observed variability in shape of the PDF caused by accumulation and melting events. The spatial distribution of SWE presented in Skaugen (2007) could, however, be applied only to snow covered areas, and did not take into account the development of snow-free areas in a catchment. In order to take the method a step further and making it suitable for

\section{HESSD}

8, 11485-11518, 2011

\section{Modelling the spatial distribution of snow water equivalent}

T. Skaugen and F. Randen

Title Page

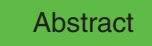

Introduction

Conclusions

Tables

References

Figures

14

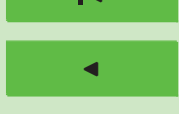

$\rightarrow 1$

Back

Close

Full Screen / Esc

Printer-friendly Version

Interactive Discussion 
implementation in a hydrological model, changes in SCA is derived from the spatial PDF of SWE and the intensity of the melting event.

Correlation between snowfall events and also between accumulated SWE and melt plays a crucial role in the proposed method for estimating the spatial PDF of SWE. In

5 our study we discuss how the correlation between melt and SWE and the hysteresis effect may be linked.

The hydrological model used operationally in Norway for flood forecasting is the Swedish HBV model (Sælthun, 1996; Bergström, 1992; Killingtveit and Sælthun, 1995). This model has been the dominant operational hydrological model in the Nordic 10 countries for several decades and is fitted with a snow routine in which the spatial distribution of snow is modelled as the sum of uniform- and log-normally distributed snowfall events. In this study we will compare modelled results of spatial moments of SWE (mean and standard deviation) and SCA, modelled with the snow distribution routine of the HBV model and the model developed in this paper against observed values. 15 Finally we will compare runoff predictions and simulations of SWE and SCA by the HBV model using both the current snow distribution routine and the new model. The main objective of this paper is to present a method for estimating the spatial PDF of SWE at the catchment scale through estimating the temporally varying spatial moments of SWE while taking changes in SCA into account.

\section{Method}

\subsection{Unit fields}

In Skaugen (2007), the PDF of accumulated SWE was approximated as a correlated sum of gamma distributed unit fields, $y(x)$, where $x$ represents space. For the remainder of this paper the unit $y(x)$ is denoted $y$. The unit fields of snowfall are distributed in space according to a two-parameter gamma distribution, $y=G\left(v_{0}, \alpha_{0}\right)$ with PDF:

\section{HESSD}

8, 11485-11518, 2011

\section{Modelling the spatial distribution of snow water equivalent}

T. Skaugen and F. Randen

Title Page

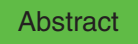

Introduction

Conclusions

Tables

References

Figures

14

4

Back

Close

Full Screen / Esc

Printer-friendly Version

Interactive Discussion $\rightarrow$ I

$>$

Interactive Discussion

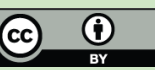


$f_{\alpha_{0}, v_{0}}(y)=\frac{1}{\Gamma\left(v_{0}\right)} \alpha_{0}^{v_{0}} y^{v_{0}-1} e^{-\alpha_{0} y} \quad \alpha_{0}, v_{0}, y>0$

HESSD

where $\alpha_{0}$ and $v_{0}$ are parameters. The mean of the unit equals $E(y)=v_{0} / \alpha_{0}$ and the variance equals $\operatorname{Var}(y)=v_{0} / \alpha_{0}^{2}$. The choice of distribution is motivated partly from studies reporting the gamma distribution as a suitable choice for the spatial distribution 5 of precipitation (Onof et al., 1998; Mackay et al., 2001), SWE (Kutchment and Gelfan, 1996; Skaugen, 2007) and snow-depth (Egli et al., 2011) and partly because of the practical mathematical features of the gamma distribution. The method applied in this paper is to estimate the spatial conditional mean, $E\left(z^{\prime}(t)\right)$ and variance, $\operatorname{Var}\left(z^{\prime}(t)\right)$ of accumulated SWE, $z^{\prime}(t)$, as functions of the units, $y$. The spatial PDF of SWE is subsequently modelled as a gamma distribution with parameters:

$v=\frac{E\left(z^{\prime}(t)\right)^{2}}{\operatorname{Var}\left(z^{\prime}(t)\right)}$ and $\alpha=\frac{E\left(z^{\prime}(t)\right)}{\operatorname{Var}\left(z^{\prime}(t)\right)}$

The distribution of $z^{\prime}$ does not contain zeros and is hereafter called conditional (i.e. conditional on snow). For the non-conditional PDF of SWE, which also includes zeros, the variable SWE is denoted $z$.

15 During the snow season, the snowpack may experience series of melting and accumulation events. It is obvious that these two processes have different spatial frequency distributions, and are differently correlated in space. Estimating the spatial variance of SWE after a series of alternating melt and accumulation events is thus a challenge and must include the covariance between the units. Furthermore, SCA varies throughout the season, which necessarily gives a non-homogeneous spatial field of SWE. In this study, SCA is set equal to 1 (full coverage) for every snowfall event, whereas a melting event implies a reduction in coverage. The chosen approach for assessing the spatial moments of SWE is to represent melting and accumulation events separately in the covariance matrix and let the spatial moments be weighted by changes in SCA.

\section{Modelling the spatial distribution of snow water equivalent}

T. Skaugen and F. Randen

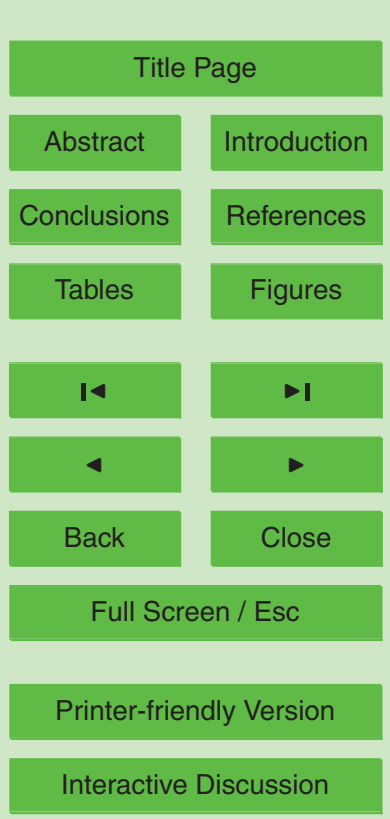




\subsection{Moments and parameters of the gamma distribution of an individual snowfall event}

HESSD

We start the procedure for determining the spatial moments of SWE by investigating a simple case, namely a single snowfall event. According to Skaugen (2007) the spatial 5 mean of a snowfall event that comprises $n$ units, $z^{\prime}(t)=\sum_{i=1}^{n(t)} y_{i}$, can be written as;

$E\left(z^{\prime}(t)\right)=\sum_{i=1}^{n} E\left(y_{i}\right)=n \frac{v_{0}}{\alpha_{0}}$,

and the variance as:

$\operatorname{Var}\left(z^{\prime}(t)\right)=\sum_{i=1}^{n(t)} \operatorname{Var}\left(y_{i}\right)+2 \sum_{i<j} \operatorname{Cov}\left(y_{i}, y_{j}\right)$.

Note that we have $n(n-1)$ covariance elements since the trace of the covariance matrix consists of the variance for each individual $y$. We estimate the covariance between the units as the average covariance over the $n(n-1)$ pairs of units, and equal to a fraction $c(n)$ of the $c(n) \frac{v_{0}}{\alpha_{0}^{2}}$. This is a departure from Skaugen (2007) where $c$ is a tuned, nondynamic value and not a function of the number of units $n$. The variance of $z^{\prime}(t)$ is thus:

$15 \operatorname{Var}\left(z^{\prime}(t)\right)=n \frac{v_{0}}{\alpha_{0}^{2}}+n(n-1) c(n) \frac{v_{0}}{\alpha_{0}^{2}}=n \frac{v_{0}}{\alpha_{0}^{2}}(1+(n-1) c(n))$.

Since $c(n)$ is the ratio between covariance and variance, it is thus the average correlation for the $n(n-1)$ pairs of units and equal to:

$c(n)=\frac{\operatorname{Var}\left(\left(z^{\prime}(t)\right) /\left(v_{0} / \alpha_{0}^{2}\right)\right)-n}{n(n-1)}$.

Modelling the spatial distribution of snow water equivalent

T. Skaugen and F. Randen

\section{Title Page}

Abstract Introduction

Conclusions References

Tables Figures

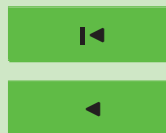

$>1$

Back

Close

Full Screen / Esc

Printer-friendly Version

Interactive Discussion

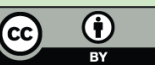


The estimation of the moments for a single event of $n$ units is thus quite straightforward. The values for $v_{0}$ and $\alpha_{0}$ can be calibrated or we can estimate the spatial conditional mean and standard deviation from historical precipitation events. From analysis of a 19 year long timeseries of precipitation, the spatial conditional mean $(m)$ and standard 5 deviation ( $s$ ) of precipitation were found to follow a functional relationship of the type, $s=a m^{h}$ (Skaugen and Andersen, 2010). If we choose the unit event to have a mean of $m=0.1$ [mm], the corresponding standard deviation is estimated from $s=a m^{h}$ and we can determine $v_{0}$ and $\alpha_{0}$ by Eq. (2). The moments of SWE for a single event can be estimated similarly and thus the correlation coefficient in Eq. (6) can be determined. 10 The average correlation $c(n)$ is a declining function of $n$, which corresponds with the results of Zawadski (1973), who found that the temporal correlation of precipitation is a rapidly declining function of time. To estimate the conditional moments from individual snowfall events, we have no apparent use for the estimate of the covariance between the units. The three following subsections show, however, how sequences of melting and accumulation events, together with changes in SCA, complicate the estimate of the spatial moments of SWE. The chosen way to deal with the complexity is to include estimates of the covariance between the units.

\subsection{Accumulation events on a previous snow reservoir}

Let the snow reservoir, consisting of $n$ units, be increased by a new snowfall of $u$ units. Our task is to estimate the moments of the new spatial PDF of SWE. If the snow reservoir prior to the snowfall event had a snow coverage equal to $\mathrm{SCA}_{t-1}$, the posterior $S C A$ is set equal to full coverage, $S_{C A}=1$. We determine the mean and the variance for the previously covered part $\mathrm{SCA}_{t-1}$ and newly covered part (1-SCA $\left.\mathrm{SC}_{t-1}\right)$ separately. The moments for these two areas are assumed independent and the moments for the 25 new totally covered area are estimated as:

$E\left(z^{\prime}(t)\right)=\operatorname{SCA}_{t-1} E\left(z^{\prime}(t)\right)_{\mathrm{SCA}_{t-1}}+\left(1-\mathrm{SCA}_{t-1}\right) E\left(z^{\prime}(t)\right)_{\left(1-\mathrm{SCA}_{t-1}\right)}$
HESSD

$8,11485-11518,2011$

Modelling the spatial distribution of snow water equivalent

T. Skaugen and F. Randen

Title Page

Abstract

Introduction

Conclusions

Tables

References

Figures

14

4

Back

Full Screen / Esc

Printer-friendly Version

Interactive Discussion 
and

$\left.\operatorname{Var}\left(z^{\prime}(t)\right)=\mathrm{SCA}_{t-1}^{2} \operatorname{Var}\left(z^{\prime}(t)\right)_{\mathrm{SCA}_{t-1}}+\left(1-\mathrm{SCA}_{t-1}\right)^{2} \operatorname{Var}\left(z^{\prime}(t)\right)_{\left(1-\mathrm{SCA}_{t-1}\right.}\right)$.

HESSD

Hence, the task is to estimate the mean and variance for the two areas $\mathrm{SCA}_{t-1}$ and $1-\mathrm{SCA}_{t-1}$, thus $E\left(z^{\prime}(t)\right)_{\mathrm{SCA}_{t-1}}, E\left(z^{\prime}(t)\right)_{\left(1-\mathrm{SCA}_{t-1}\right)} \operatorname{Var}\left(z^{\prime}(t)\right)_{\mathrm{SCA}_{t-1}}$ and $5 \operatorname{Var}\left(z^{\prime}(t)\right)_{\left(1-\mathrm{SCA}_{t-1}\right)}$.

\subsubsection{The mean}

The mean is simply estimated as the sum of the units times the unit mean. For the two areas, the moments are $E\left(z^{\prime}(t)\right)_{\mathrm{SCA}_{t-1}}=(n+u) v_{0} / \alpha_{0}$ and $E\left(z^{\prime}(t)\right)_{\left(1-\mathrm{SCA}_{t-1}\right)}=u v_{0} / \alpha_{0}$, respectively. The mean for the new totally covered area is thus:

$E\left(z^{\prime}(t)\right)=\operatorname{SCA}_{t}(n+u) \frac{v_{0}}{\alpha_{0}}+\left(1-\operatorname{SCA}_{t}\right) u \frac{v_{0}}{\alpha_{0}}$

\subsubsection{The variance}

For the newly covered area, $1-\mathrm{SCA}_{t-1}$, the variance is estimated using Eq. (5) as:

$\operatorname{Var}\left(z^{\prime}(t)\right)_{1-\mathrm{SCA}_{t-1}}=u \frac{v_{0}}{\alpha_{0}^{2}}+u \frac{v_{0}}{\alpha_{0}^{2}}(u-1) c(u)$.

For the previously covered area, it is useful to consider the covariance matrix. The 15 matrix is at all times symmetric, and we can view the additional snowfall as an extension of the elements of the matrix, so that after a snowfall event of $u$ units the original $n \times n$ matrix becomes a matrix of $(n+u) \times(n+u)$ elements. We proceed to estimate the four parts of the matrix separately $\left(\operatorname{Var}_{n \times n}, 2 \operatorname{Cov}_{n \times u}\right.$, and $\operatorname{Var}_{u \times u}$, see Fig. 1) and finally estimate $\operatorname{Var}\left(z^{\prime}(t)\right)_{\mathrm{SCA}_{t}}$ as the sum of these parts.

20 The variance of the previous $n$ events, $\operatorname{Var}_{n \times n}$ is expressed by the updated parameters of the gamma distribution at time $t-1$ (by Eq. 2) and equal to $\operatorname{Var}_{n \times n}=\frac{v}{\alpha^{2}}$. This variance may differ from that obtained by Eq. (5), using $n$, because there may be a history

Modelling the spatial distribution of snow water equivalent

T. Skaugen and F. Randen

Title Page

Abstract Introduction

Conclusions References

14

4

Back

Close

Full Screen / Esc

Printer-friendly Version

Interactive Discussion

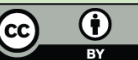


of accumulation and melting events which prevents $\operatorname{Var}_{n \times n}$ from being a straightforward function of $n$, as is the case in Eq. (5). The sum of the elements in the covariance matrix for $\operatorname{Cov}_{n \times u}$ (and $\operatorname{Cov}_{u \times n}$ ) is $u \cdot n \frac{v_{0}}{\alpha_{0}^{2}} c_{\text {acc }}$ and the sum for $\operatorname{Var}_{u \times u}$ is $u \frac{v_{0}}{\alpha_{0}^{2}}+u(u-1) \frac{v_{0}}{\alpha_{0}^{2}} c(u)$. The correlation coefficient, $c_{\mathrm{acc}}$, is estimated as if the total variance $\operatorname{Var}\left(z^{\prime}(t)\right)_{\mathrm{SCA}_{t}}$ and $5 \operatorname{Var}_{n \times n}$ were estimated using Eq. (5) with $u+n$ and $n$ elements respectively. This is an approximation since we do not know if $\operatorname{Var}_{n \times n}$ is estimated by Eq. (5) or may be the result of previous accumulation and melting events as discussed above. The equation $\operatorname{Var}_{(n+u) \times(n+u)}=\operatorname{Var}_{n \times n}+2 \operatorname{Cov}_{n \times u}+\operatorname{Var}_{u \times u}$ is then solved for $c_{\text {acc }}$. The correlation coefficient $C_{\text {acc }}$, is thus estimated as:

$10(n+u) \frac{v_{0}}{\alpha_{0}^{2}}+(n+u)(n+u-1) \frac{v_{0}}{\alpha_{0}^{2}} c(n+u)=n \frac{v_{0}}{\alpha_{0}^{2}}+n(n-1) \frac{v_{0}}{\alpha_{0}^{2}} c(n)$

$$
+2 u \cdot n \frac{v_{0}}{\alpha_{0}^{2}} c_{\mathrm{acc}}+u \frac{v_{0}}{\alpha_{0}^{2}} u(u-1) \frac{v_{0}}{\alpha_{0}^{2}} c(u)
$$

which gives

$(n+u)(n+u-1) c(n+u)=n(n-1) c(n)+2 u \cdot n c_{\mathrm{acc}}+u(u-1) c(u)$ and finally

$c_{\mathrm{acc}}=\frac{(n+u)(n+u-1) c(n+u)-n(n-1) c(n)-u(u-1) c(u)}{2 u \cdot n}$.

As the four parts of the covariance matrix describing the variance of the previously covered area now are estimated, we can write $\operatorname{Var}\left(z^{\prime}(t)\right)_{\mathrm{SCA}_{t-1}}$ as

$\operatorname{Var}\left(z^{\prime}(t)\right)_{\mathrm{SCA}_{t-1}}=\frac{v}{\alpha^{2}}+2 u \cdot n \frac{v_{0}}{\alpha_{0}^{2}} c_{\mathrm{acc}}+u \frac{v_{0}}{\alpha_{0}^{2}}+u(u-1) \frac{v_{0}}{\alpha_{0}^{2}} c(u)$

and finally, the spatial variance of the total snow covered area, $\mathrm{SCA}_{t}$ as:
HESSD

8, 11485-11518, 2011

Modelling the spatial distribution of snow water equivalent

T. Skaugen and F. Randen

Title Page

Abstract Introduction

Conclusions References

Tables Figures

14

4

Back

Close

Full Screen / Esc

Printer-friendly Version

Interactive Discussion 


\subsection{Melting events}

Let the snow reservoir, consisting of $n$ units, be reduced by $u$ units after a melting event. The snow coverage before and after the melting event is $\mathrm{SCA}_{t-1}$ and $\mathrm{SCA}_{t}$ respectively, where $\mathrm{SCA}_{t}<\mathrm{SCA}_{t-1}$. We set $\mathrm{SCA}_{t-1}$ as 1 , so that $\mathrm{SCA}_{t}$ is the relative

5 reduction in snow coverage due to melting, and not the catchment value. The reduction in snow coverage poses a problem in that we have to separate between non-conditional - (the area includes a fraction of zero values) and conditional moments. We thus have to determine the spatial moments for the area of the new coverage $\mathrm{SCA}_{t}$ (conditional moments) and for the area which includes the previously covered part, $\mathrm{SCA}_{t-1}$ (nonconditional moments).

\subsubsection{The mean}

The non-conditional mean after the melting event, is estimated as:

$E(z(t))=(n-u) \frac{v_{0}}{\alpha_{0}}$

and the conditional mean is

$E\left(z^{\prime}(t)\right)=E(z(t)) / \mathrm{SCA}_{t}=\frac{1}{\mathrm{SCA}_{t}}(n-u) \frac{v_{0}}{\alpha_{0}}$.

We note that the difference in conditional means before and after the melting event is

$E\left(z^{\prime}(t-1)\right)-E\left(z^{\prime}(t)\right)=\frac{v_{0}}{\alpha_{0}}\left(n-(n-u) / S C A_{t}\right)=\frac{v_{0}}{\alpha_{0}} \frac{u^{\prime}}{\mathrm{SCA}_{t}}$

where $u^{\prime}$ is the conditional number of melted units.

\subsubsection{The variance}

20 When assessing the conditional variance after the melting event, the melting event is seen as an extension of the elements of the covariance matrix similar as for

HESSD

$8,11485-11518,2011$

Modelling the spatial distribution of snow water equivalent

T. Skaugen and

F. Randen

Title Page

Abstract

Introduction

Conclusions

References

Tables

Figures

14

4

Back

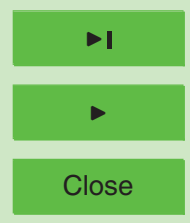

Full Screen / Esc

Printer-friendly Version

Interactive Discussion 
accumulation events. The original $n \times n$ matrix becomes, after melting $u^{\prime}$ units, a matrix of $\left(n+u^{\prime}\right) \times\left(n+u^{\prime}\right)$ elements. We proceed, as in the case of accumulation, to estimate the four parts of the matrix separately $\left(\operatorname{Var}_{n \times n}, 2 \operatorname{Cov}_{u^{\prime} \times n}\right.$ and $\operatorname{Var}_{u^{\prime} \times u^{\prime}}$, see Fig. 2) and finally estimate $\operatorname{Var}\left(z^{\prime}(t)\right)_{\mathrm{SCA}_{t}}$ as the sum:

$5 \operatorname{Var}\left(z^{\prime}(t)\right)_{\mathrm{SCA}_{t}}=\operatorname{Var}_{n \times n}+2 \operatorname{Cov}_{u^{\prime} \times n}+\operatorname{Var}_{u^{\prime} \times u^{\prime}}$.

The only possible negative contribution in Eq. (10) is $\operatorname{Cov}_{u^{\prime} \times n}$, since both $\operatorname{Var}_{n \times n}$ and $\operatorname{Var}_{u^{\prime} \times u^{\prime}}$ are by definition positive. Negative covariance implies that melting is negatively correlated with SWE, i.e. melting is more intense from areas with less SWE.

The variance of the $n$ events prior to the melting, $\operatorname{Var}_{n \times n}$ is expressed by the updated

parameters of the gamma distribution (Eq. 2) at time $t-1$ and equal to $\operatorname{Var}_{n \times n}=\frac{v}{\alpha^{2}}$.

The negative covariance contribution $\operatorname{Cov}_{n \times u^{\prime}}\left(\right.$ or $\operatorname{Cov}_{u^{\prime} \times n}$ between melt and SWE is estimated as:

$\operatorname{Cov}_{n \times u^{\prime}}=2 u^{\prime} n \frac{v_{0}}{\alpha_{0}^{2}} c_{\text {mlt }}$.

The nature of the correlation $c_{\mathrm{mlt}}$, is unknown, but we can estimate the limiting values 15 for no melt $\left(u^{\prime}=0\right)$ and complete melt $\left(u^{\prime}=n\right)$. When $u^{\prime}=0$, the covariance is obviously zero, but for the latter case, the total variance becomes zero and we can estimate $c_{\mathrm{mlt}}$ from Eq. (10), $\operatorname{Var}_{n \times n}+\operatorname{Var}_{u^{\prime} \times u^{\prime}}=2 \operatorname{Cov}_{u^{\prime} \times n}$, which gives:

$\frac{v}{\alpha^{2}}+n \frac{v_{0}}{\alpha_{0}^{2}}+n(n-1) \frac{v_{0}}{\alpha_{0}^{2}} c(n)=2 n^{2} \frac{v_{0}}{\alpha_{0}^{2}} c_{\mathrm{mlt}}(n)$

and:
HESSD

$8,11485-11518,2011$

Modelling the spatial distribution of snow water equivalent

T. Skaugen and

F. Randen

Title Page

Abstract

Introduction

Conclusions

References

Tables

Figures

14

4

Back

Close

Full Screen / Esc

Printer-friendly Version

Interactive Discussion 
For specific values of $u^{\prime}\left(u^{\prime} \leq n\right)$, we approximate $c_{\text {mlt }}\left(u^{\prime}\right)$ as a linearly increasing function of $u^{\prime}$ :

$c_{\text {mlt }}\left(u^{\prime}\right)=\frac{u^{\prime}}{n}\left(\frac{1}{2 n} \frac{v \alpha_{0}^{2}}{n \alpha^{2} v_{0}}+1+(n-1) c(n)\right)$.

The variance of the melting events is estimated using Eq. (5)

${ }_{5} \operatorname{Var}_{u^{\prime} \times u^{\prime}}=u^{\prime} \frac{v_{0}}{\alpha_{0}^{2}}+u^{\prime}\left(u^{\prime}-1\right) \frac{v_{0}}{\alpha_{0}^{2}} c\left(u^{\prime}\right)$.

Finally, the total variance of the new conditional distribution after a melting event is computed as:

$\operatorname{Var}\left(z^{\prime}(t)\right)=\frac{v}{\alpha^{2}}-2 u^{\prime} n \frac{v_{0}}{\alpha_{0}^{2}} c_{\mathrm{mlt}}\left(u^{\prime}\right)+u^{\prime} \frac{v_{0}}{\alpha_{0}^{2}}+u^{\prime}\left(u^{\prime}-1\right) \frac{v_{0}}{\alpha_{0}^{2}} c\left(u^{\prime}\right)$.

\subsection{Estimating changes in snow covered area (SCA)}

10 After a snowfall event, the SCA for a catchment or part of a catchment is set equal to 1 in the HBV model. The same procedure for estimating SCA after an accumulation event is applied here. For a melting event, however, the estimate of changes in SCA is somewhat more elaborate. In Dingman (1994) the energy requirements for transforming a snowpack into meltwater is stated as: $Q=Q_{1}+Q_{2}+Q_{3}$ where the different energy quantities refer to warming the snowpack to a uniform temperature of $0{ }^{\circ} \mathrm{C}$ degrees $\left(Q_{1}\right)$, producing a certain fraction of meltwater contained in the snowpack $\left(Q_{2}\right)$ and transforming the snow into meltwater $\left(Q_{3}\right)$.

\section{HESSD}

$8,11485-11518,2011$

Modelling the spatial distribution of snow water equivalent

T. Skaugen and F. Randen

\section{Title Page}

Abstract Introduction

Conclusions References

14

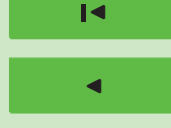

$>1$

Back

Close

Full Screen / Esc

$Q_{1}=-c_{i} \rho_{\mathrm{w}} h_{\mathrm{m}}\left(T_{\mathrm{s}}-T_{\mathrm{m}}\right)$

$Q_{2}=h_{\text {wret }} \rho_{\mathrm{w}} \lambda_{\mathrm{f}}$

20

$Q_{3}=\left(h_{\mathrm{m}}-h_{\text {wret }}\right) \rho_{\mathrm{w}} \lambda_{\mathrm{f}}$

Printer-friendly Version

Interactive Discussion 
where $h_{\mathrm{m}}$ is SWE, $h_{\text {wret }}$ is free water stored in the snow pack (usually a fixed percentage of SWE in hydrological models), $T_{\mathrm{s}}$ and $T_{\mathrm{m}}$ are snowpack - and melting point temperatures respectively and the rest of the parameters are constants. All the energy quantities are linear functions of the depth, $h$ of SWE, so an assumption that areas 5 with the smallest SWE are the first to become snow free, due to smaller energy requirements, appears reasonable. This assumption is used to estimate the reduction in SCA after a melting event. Previous sections propose a gamma distribution, $f_{\mathrm{a}}$ with parameters $v$ and $\alpha$ as a model for the PDF of SWE. $f_{\mathrm{a}}\left(z^{\prime}\right)=\frac{1}{\Gamma(v)} \alpha^{v} x^{\nu-1} e^{-\alpha z^{\prime}} \alpha, v$, $z^{\prime}>0$. We also assume that the spatial frequency of melt has a gamma distribution, $10 f_{\mathrm{s}}$. Various studies suggest gamma- or log-normal distribution for melting (Skaugen, 2007; Essery and Pomeroy, 2004), but a uniform distribution has also been used (Liston, 1999; Egli and Jonas, 2009). It is further assumed that the parameters of $f_{\mathrm{s}}$ follow the same principles as for accumulation, i.e. that the moments can be estimated using Eqs. 3) and (5) with $u^{\prime}$ replacing $n$. At all times $u^{\prime} \leq n$, which implies that until the final melting event occurs, $f_{\mathrm{s}}$ is more skewed to the left than $f_{\mathrm{a}}$.

In accordance with a negative correlation between snow depth and melt, we state that all points with SWE values less than some value $X$ will be left snow free. This gives us a reduction in the spatial extent of SCA equal to $a=\int_{0}^{X} f_{\mathrm{a}} d x$. The value of $X$ is thus the limit where the frequencies of the melt distribution $f_{\mathrm{s}}$, are higher or equal 20 to the frequencies of the accumulation distribution, $f_{\mathrm{a}}$. Also, since $f_{\mathrm{s}}$ is not bounded to the right, some areas with higher values of SWE than $X$ will be left snow-free after a melting event. For example, if we consider discrete PDFs of the accumulation and melt distribution $\left(p_{\mathrm{a}}\right.$ and $p_{\mathrm{s}}$, then a fraction of the total snow-covered area will contain SWE values in the interval defined by, say $S W E=X+\mathrm{x}$. A smaller fraction of the area with values in the interval SWE $=X+\mathrm{x}$, will be left snow-free since $p_{\mathrm{s}}(X+X)$ is smaller than $p_{\mathrm{a}}(X+X)$. When we consider the total snow-covered area, a fraction of all the frequencies of the accumulation distribution $f_{\mathrm{a}}$ for SWE values higher than $X$ will be

\section{HESSD}

$8,11485-11518,2011$

\section{Modelling the spatial distribution of snow water equivalent}

T. Skaugen and F. Randen

Title Page

Abstract

Introduction

Conclusions

Tables

References

Figures

14

4

Back

Close

Printer-friendly Version

Interactive Discussion 
left snow-free. If these frequencies are summed, $1-s=\int_{X}^{\infty} f_{\mathrm{s}}$ (where $s=\int_{0}^{X} f_{\mathrm{s}}$ ) they will thus represent the area for SWE values higher than $X$ that are left snow free. The reduction in SCA after a melting event is thus

$\mathrm{SCA}_{\text {red }}=a+1-s$.

5 Recall that the reduction in $\mathrm{SCA}_{\text {red }}$ is relative, i.e. it is the reduction from the previous snow-cover, which is also the probability space of both $f_{\mathrm{a}}$ and $f_{\mathrm{s}}$, and thus equal to 1.

\section{Results}

In this section we first present how the results of the proposed algorithms for estimating the spatial moments of SWE and SCA (hereafter called the G_model) compare with ob10 served data. Then we present data that justifies the assumption of gamma distributed snowmelt. Finally, we show results from the implementation of the G_model in a hydrological model. For five catchments we compare the model performances of the HBV model using both the G_model and classic, lognormal snow distribution (LN_model) currently used in the HBV model. The LN_model uses a uniform spatial distribution of 15 SWE up to a specified threshold of accumulated SWE. For additional snowfall events, each snowfall event is log-normally distributed through a calibrated coefficient of variation (CV) at a specified set of quantiles, i.e. each additional snowfall event has a spatial PDF of fixed shape (through the calibrated $\mathrm{CV}$ ) regardless of its intensity. The spatial distribution of melt is uniform and reduction in SCA occurs when the SWE associated with a quantile becomes zero. The reduction in SCA is thus the sum of quantiles with zero SWE. The snow routine of the HBV model does not keep track of the spatial moments of accumulated SWE so it is not straightforward to assess the modelled spatial PDF for this model. In this study the SWE values for the different quantiles are fitted to a lognormal distribution, and the spatial moments are derived from the parameters of the fitted distribution.

\section{HESSD}

8, 11485-11518, 2011

Modelling the spatial distribution of snow water equivalent

T. Skaugen and F. Randen

Title Page

Abstract Introduction

Conclusions

Tables

References

Figures

14

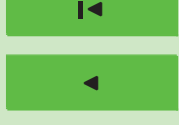

$\rightarrow$

Back

Close

Full Screen / Esc

Printer-friendly Version

Interactive Discussion 


\subsection{Comparing estimated spatial mean standard deviation and SCA with observed data}

In order to assess the performance of the G_model we need to compare the results against observed data. Two such data sets exist in Norway. The first is the data set 5 from Norefjell in Southern Norway and was previously presented in Skaugen (2007). At Norefjell snow surveys at 1000 m a.s.l. were carried out every second week along a $2 \mathrm{~km}$ long snow course. Snow depth was measured every $10 \mathrm{~m}$ and density measurements were taken twice for each snow course. This provided a time series of snow course data covering an entire snow season from the start of accumulation to the end of the melting period. Twenty five surveys were made at this site. The second data set is from the Norwegian Water Resources and Energy Directorate (NVE) research site for snow at Filefjell, southern Norway (Stranden and Grønsten et al., 2011). The site is situated at $1000 \mathrm{~m}$ a.s.I., and has a stable snow cover throughout the months of November-April. The vegetation is grass and willow thicket $(<50 \mathrm{~cm})$. About 45 stakes are placed at a flat stretch of $450 \mathrm{~m}$, ensuring that exactly the same point is measured for each sample. At the stakes snow depths and densities were usually measured once a week throughout the melting season. For each survey of snow depths, snow density was measured at four locations. Eight surveys were made at this site. Both these sites represent areas smaller than the typical catchments scale, but measurements of the spatial moments of SWE at the catchment scale is not known in Norway. SCA is estimated for the sites by counting the non-zero fraction of measurements. From the observed conditional spatial mean of SWE and SCA, we can derive the nonconditional values of accumulation and melt ( $n$ and $u$ ), which are input to the snow distribution models. The output from the models is the conditional- mean and standard deviation and SCA.

Figures 3 (Norefjell) and 4 (Filefjell) show observed and estimated (by Eqs. 7-9, and 14 for the G_model) conditional-mean and standard deviation and SCA. For the G_model the parameters $\alpha_{0}$ and $v_{0}$ are calibrated to yield an optimal fit of the spatial

\section{HESSD}

8, 11485-11518, 2011

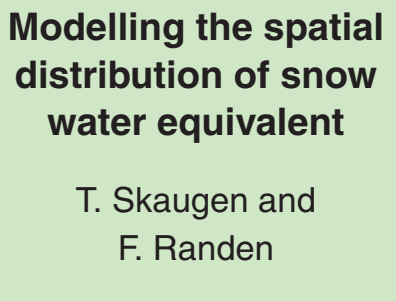

Title Page

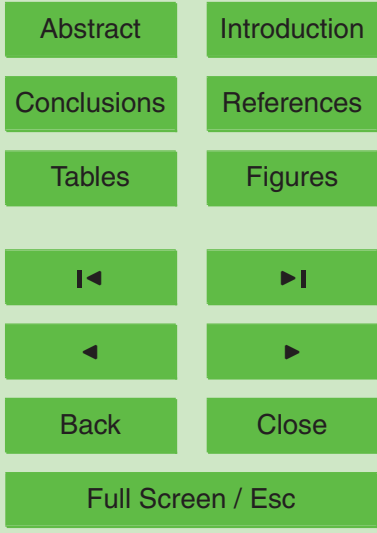

Printer-friendly Version

Interactive Discussion 
standard deviation, whereas the CV is calibrated for the $\mathrm{LN}$.model for the same purpose.

For calibrated values of $\alpha_{0}, v_{0}$ and $\mathrm{CV}$, the agreement between simulated and observed values (Figs. 3 and 4 ) is quite good for both models. The LN_model has a 5 better prediction of the conditional mean for Norefjell whereas the opposite is the case for Filefjell. For the conditional standard deviation the G_model has a better fit for both sites, which is also reflected in the estimated CV. SCA is reasonably well predicted for both sites by both models. When SCA reduces, the simulated conditional moments deviate from the observed for both models.

10 For uncalibrated values of $\alpha_{0}, v_{0}$ ( $\mathrm{CV}$ is still calibrated) the agreement between the results for the G_model and the observed is still quite good, and do not deteriorate much from the calibrated results (Figs. 5 and 6). This result implies that the G_model can be parameterized using observed (precipitation) data, and reduces hence, without much loss in precision, the number of parameters to be calibrated by one.

\subsection{The spatial distribution of snow melt}

For the snow seasons 2009-2010 and 2010-2011 an attempt to measure the spatial distribution of snow melt took place at the site at Filefjell. The spatial distribution of snowmelt was estimated from differences in SWE measured at each stake after a melting event. From the two seasons of measurements seven events could be anal20 ysed. Figure 7 shows that a gamma distribution is entirely plausible and that more intense melting gives a less skewed spatial distribution. These findings thus support the assumption that the spatial frequency distribution of melt can also be modelled as a sum of correlated gamma distributed variables.

\subsection{Implementing the G_model in the HBV model}

25 The algorithms for estimating the spatial moments of SWE and thus the parameters of the spatial PDF of SWE are implemented in the HBV model. Input to HBV

\section{HESSD}

8, 11485-11518, 2011

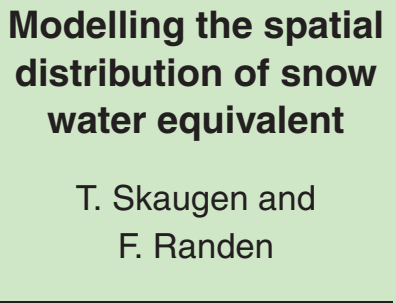

Title Page

Abstract

Introduction

Conclusions

Tables

References

Figures

14

4

Back

Close

Full Screen / Esc

Printer-friendly Version

Interactive Discussion 
is temperature and precipitation. The snow-routine is a semi-distributed degree-day model so that the moisture accounting is performed separately for ten elevation zones. The Norwegian version of the HBV uses the lognormal spatial distribution for SWE as described above (the LN_model) and in Killingtveit and Sælthun (1995). Runoff dy5 namics are controlled by two linear reservoirs with three outlets. When testing the new snow distribution model, the G_model replaces the original LN_model and all other routines are kept as in the original model. The HBV model with its two snow distribution models is calibrated and validated for five Norwegian catchments located at relatively high altitudes where snow is of significant hydrological importance. Two versions of the 10 model were calibrated. The original HBV model (HBV_LN) and the HBV model with the new snow distribution routine, where $\alpha_{0}$ and $v_{0}$ are estimated from precipitation data (HBV_G). The models were automatically calibrated using a Marcov Chain Monte Carlo (MCMC) routine programmed in $\mathrm{R}$ (Soetaert and Petzholdt, 2010). Table 1 shows the calibration and validation results for the 5 catchments.

154 Discussion

\subsection{Complex variance-mean relationship and correlation between melt and SWE}

In Figs. 3-6 we observe an increase in observed spatial standard deviation at the onset of the melting period. For both Norefjell and Filefjell the maximum standard deviation can be seen at the time of the first reduction in the spatial mean of SWE (at time 22 for Norefjell and time 5 for Filefjell). The measurements at time 8 is the highest for Filefjell, but this estimate of spatial standard deviation is based on only three measurements (SCA is 0.11) and is therefore uncertain to such a degree that it can be disregarded. The standard deviation simulated by the G_model captures this phenomenon to some degree in that the highest simulated standard deviation coincides in time with the observed, whereas the spatial standard deviation of the LN_model continues to increase

\section{HESSD}

8, 11485-11518, 2011

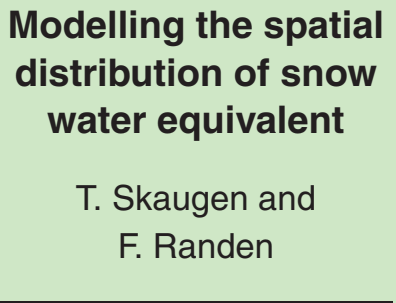

Title Page

Abstract

Introduction

Conclusions

Tables

References

Figures

14

4

Back

Full Screen / Esc

Printer-friendly Version

Interactive Discussion $\rightarrow$ I

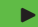

Close 
after this time. If we consider the last two terms in Eq. 10 (Eqs. 11 and 13), we find that these terms regulate whether the changes to the variance prior to the melting event, $\operatorname{Var}_{n \times n}=\frac{v}{\alpha^{2}}$, are negative or positive. At the start of the melting season, the negative contribution of Eq. (11) is more than compensated by Eq. (13) and the variance is in5 creased or stable. As the melting season proceeds, the negative contribution increases and the total variance decreases. A different (non- linear) function for $c_{\text {mlt }}$ could perhaps give a better fit to the observed data, but this was not investigated. It is interesting to note that as a mathematical consequence the sign of the correlation between SWE and melt comes out negative, since otherwise the variance would never decrease. The 10 sign of this correlation has been debated in the literature (Skaugen, 2007; Essery and Pomeroy, 2004; Faria, 2000), but it follows from the derivation of the spatial variance of SWE in this paper, and also from physical reasoning (that less energy is required to melt smaller amounts of SWE) that correlation between melt and SWE is negative.

\subsection{Snow distribution models in hydrological models}

Table 1 shows that, according to the Nash-Sutcliffe R2, both models perform well and quite similarly for the five catchments. The validation results are slightly better with the G_model for the catchments Atnasjø and Narsjø, and slightly inferior for the other catchments. Assessments of snow variables that are simulated (SWE and SCA), but not the objective for calibration (runoff) can be made. Figures 8 and 9 show observed and sim20 ulated runoff, simulated SWE and SCA for the catchments Narsjø and Junkerdalselv respectively. In the bottom panels of the figures we also find SCA estimates derived from satellite (MODIS) optical images. Runoff and SCA (panels a and c) are plotted for spring 2007 and the snow season of 2008 and SWE (panel b) is plotted for the entire validation period (1981-2008). For the Narsjø catchment (Fig. 8) the G_model gave the 25 better fit to the observed, mainly due to more simulated snow. The simulations of SCA, however, were very similar for the G_model and for the LN_Model and overestimated for the 2007 season and fairly well simulated for the 2008 season. For the Junkerdal catchment (Fig. 9) the HBV_LN model gave the better fit, but as can be seen from the

\section{HESSD}

8, 11485-11518, 2011

\section{Modelling the spatial distribution of snow water equivalent}

T. Skaugen and F. Randen

Title Page

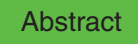

Introduction

Conclusions

Tables

References

Figures

14

$\rightarrow$

4

Back

Close

Full Screen / Esc

Printer-friendly Version

Interactive Discussion 
simulations of SWE (panel b) perhaps not for the right reasons. It is clear from Fig. 9 (panel c) that the HBV_LN model simulates too much snow which it fails to melt during spring. The result is an accumulation of SWE and perennial snow the highest altitude levels (this can also be seen from the plot of SCA (panel c). It is notable that 5 such an obvious erroneous simulation of SWE does not prevent a good precision in runoff prediction. The overestimated SWE, which in summer will produce a continuous input of melt water, is compensated for by an error where output of water is reduced. Such a compensating error may, for example, be a smaller reservoir for subsurface water. A possible explanation for why HBV_G gives a more realistic simulation of SWE 10 may be that the mutual dependencies in the modelling chain of (i) spatial moments of SWE conditioned on observed precipitation characteristics, (ii) the evolution of snowfree areas and (iii) runoff dynamics in spring, represent a rather strict conditioning that discourages unrealistic values of SWE.

Both models underestimate SCA for this catchment, but HBV_G to a higher degree 15 than HBV LN. The underestimation of SCA (and runoff) in the 2007 season by the HBV_G model for the Junkerdal catchment provides a cue for a brief discussion of the sequel of this study. The current study has been devoted to estimating the spatial PDF of SWE and to developing algorithms that relates the changes in SCA to the spatial PDS of both SWE and snow-melt. In an ongoing study we have used the algorithms developed for relating the PDFs of SWE and melt to changes in SCA to update the snow reservoir, i.e. the PDF of SWE, from satellite derived SCA. By manipulating the spatial PDF of melt, we can adjust the PDF of SWE so that the differences in observed and modelled SCA are matched. This can carried out both for satellite derived SCA higher and less than modelled SCA. Such an updating is thus totally dependent on the knowledge of the spatial PDF of SWE hence a very important feature of the current study has been to provide its estimates.

\section{HESSD}

$8,11485-11518,2011$

\section{Modelling the spatial distribution of snow water equivalent}

T. Skaugen and F. Randen

Title Page

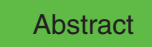

Introduction

Conclusions

Tables

References

Figures

14

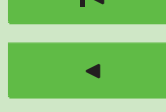

Back

Close

Full Screen / Esc

Printer-friendly Version

Interactive Discussion 


\subsection{Reducing the number of calibrated parameters in hydrological models}

Ideally we would like the operational hydrological models to provide reliable predictions for more elements in the hydrological cycle than just runoff. When hydrological models are also calibrated against other variables and quite accurate predictions are obtained, 5 the precision in runoff predictions does not necessarily increase. In fact, the opposite is seen when hydrological models are also calibrated against, for example observed SCA (Parajka et al., 2007). This is probably due to sub-optimal model structure and over-parameterisation of hydrological models. This is a challenge for the study of the interactions and interdependencies of different hydrological processes, and hinders the use of hydrological models as a tool for gaining scientific insights. In this study we have developed a model that increases the number of tuning parameters by one compared with the original model if we calibrate the parameters $\alpha_{0}$ and $v_{0}$. However, if $\alpha_{0}$ and $v_{0}$ are estimated from observed precipitation data, the number of calibrated parameters is reduced by one and equal or even better results are obtained in predicting runoff and 15 snow variables.

\section{Conclusions}

A method for estimating the spatial frequency distribution for SWE is proposed. The distribution is dynamic in that its parameters change according to melt and accumulation events.

An algorithm for estimating changes in SCA is also introduced. The model simulates spatial standard deviation and change of snow cover well when compared with observed data.

Also, when the model is implemented in a hydrological model with parameters estimated from observed precipitation data, the snow reservoir is credibly simulated. Although the number of parameters to be calibrated is reduced by one, there is no loss in precision in predicted runoff.

\section{HESSD}

8, 11485-11518, 2011

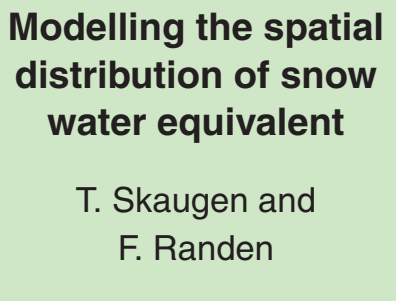

Title Page

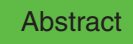

Introduction

Conclusions

Tables

References

Figures

14

4

Back

Close

Full Screen / Esc

Printer-friendly Version

Interactive Discussion 
Through the mathematical-statistical formulation of the model, the correlation between melt and SWE is necessarily negative.

In an ongoing study we use the algorithms developed for relating the PDFs of SWE and melt to changes in SCA to update the snow reservoir from satellite derived SCA

5 Acknowledgements. The help of Nils Kristian Orthe in providing the satellite derived SCA data is gratefully acknowledged.

\section{References}

Alfnes, E., Andreassen, L. M., Engeset, R. V., Skaugen, T., and Udnæs, H.-C.: Temporal variability in snow distribution, Ann. Glaciol., 38, 101-105, 2004.

Bergström, S.: The HBV model - its structure and applications, SMHI Reports Hydrology No 4, Swedish Meteorological and Hydrological Institute, Norrköping, Sweden, 1992.

Buttle, J. M. and McDonnel, J. J. Modelling the areal depletion of snowcover in a forested catchment, J. Hydrol., 90, 43-60, 1987.

Dingman, S. L.: Physical hydrology, Prentice Hall, New Jersey, USA, 1994.

15 Egli, L., Griessinger, N., and Jonas, T.: Seasonal development of spatial snow-depth variability across different scales in the Swiss Alps, Ann. Glaciol., 52, 216-222, 2011.

Egli, L. and Jonas, Y.: Hysteretic dynamics of seasonal snow depth distribution in the Swiss Alps, Geophys. Res. Lett., 36, L02501, doi:10.1029/2008GL035545, 2009.

Essery, R. and Pomeroy, J.: Implications of spatial distributions of snow mass and melt rate for snow-cover depletion: theoretical considerations, Ann. Glaciol., 38, 261-265, 2004.

Faria, D. A., Pomeroy, J., and Essery, R.: Effect of covariance between ablation and snow water equivalent on depletion of snow-covered area in a forest, Hydrol. Process., 14, 2683-2695, 2000.

Killingtveit, Å. and Sælthun, N-R.: Hydrology, Volume No. 7 in Hydropower development, NIT, 25 Trondheim, Norway, 1995.

Kutchment, L. S. and Gelfan, A. N.: The determination of the snowmelt rate and the meltwater outflow from a snowpack for modelling river runoff generation, J. Hydrol., 179, 23-36, 1996.

\section{HESSD}

8, 11485-11518, 2011

\section{Modelling the spatial distribution of snow water equivalent}

T. Skaugen and

F. Randen

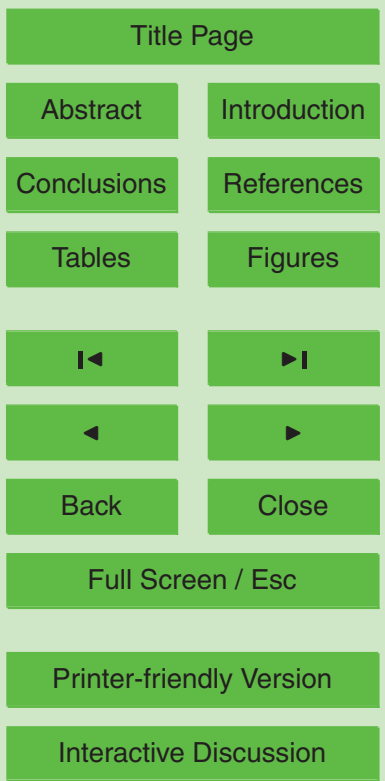


Liston, G.: Interrelationships among Snow Distribtuion, Snowmelt and Snow Cover Depletion: implications for atmospheric, hydrologic and ecologic modeling, J. Appl. Meteorol., 38, 14741487, 1999.

Luce, C. H. and Tarboton, D. G.: The application of depletion curves for parameterization of subgrid variability of snow, Hydrol. Process. 18, 1409-1422, 2004.

Luce, C. H., Tarboton, D. G., and Cooley, K. R.: Sub-grid parameterization of snow distribution for an energy and mass balance snow cover model, Hydrol. Process., 13, 1921-1933, 1999.

Mackay, N. G., Chandler, R. E., Onof, C., and Wheater, H. S.: Disaggregation of spatial rainfall fields for hydrological modelling, Hydrol. Earth Syst. Sci., 5, 165-173, doi:10.5194/hess-5$10 \quad$ 165-2001, 2001.

Martinec, J., Rango, A., and Roberts, R.: The Snowmelt-Runoff Model (SRM) users Manual, Updated Edition 1994 Version 3.2, Dept. of Geography, University of Bern, Switzerland, 1994.

Onof, C., Mackay, N. G., Oh, L., and Weather, H. S.: An improved rainfall disaggregation technique for GCMs, J. Geophys. Res., 103, 577-586, 1998.

Parajka, J., Merz, R., and Blöschl, G.: Uncertainty and multiple objective calibration in regional water balance modelling: a case study in 320 Austrian catchments, Hydrol. Process., 21, 435-446, 2007.

Pomeroy, J., Essery, R., and Toth, B.: Implications of spatial distributions of snow mass and melt rate for snow-cover depletion: observations in a subarctic mountain catchment, Ann. Glaciol., 38, 195-201, 2004.

Sælthun, N. R.: The "Nordic" HBV model, Description and documentation of the model version developed for the project Climate Change and Energy Production, NVE Publication no. 71996, Oslo, 26 pp., 1996.

Shamir, R. and Georgakaos, K. P.: Estimating snow depletion curves for American River basins using distributed snow modelling, J. Hydrol., 334, 162-173, 1998.

Skaugen, T.: Modelling the spatial variability of snow water equivalent at the catchment scale, Hydrol. Earth Syst. Sci., 11, 1543-1550, doi:10.5194/hess-11-1543-2007, 2007.

Skaugen, T. and Andersen, J.: Simulated precipitation fields with variance-consistent Interpolation, Hydrolog. Sci. J., 55, 676-686, doi:10.1080/02626667.2010.487976, 2010.

Soetaert, K. and Petzholdt, T.: Inverse Modelling, Sensitivity and Monte Carlo analysis in R Using package FME, J. Stat. Softw., 33 1-28, 2010.

\section{HESSD}

$8,11485-11518,2011$

\section{Modelling the spatial distribution of snow water equivalent}

T. Skaugen and F. Randen

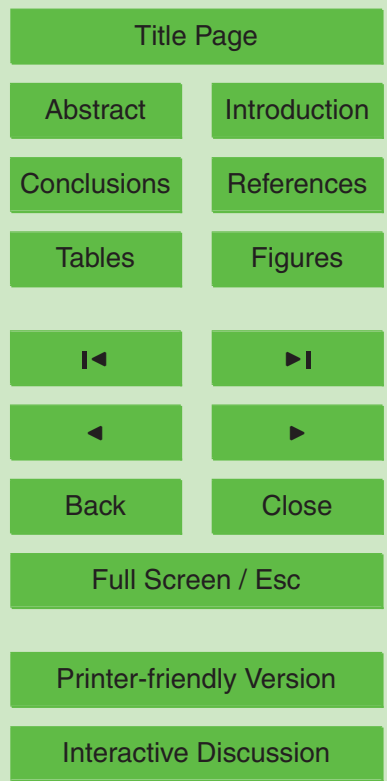


Stranden, H. B. and Grønsten, H. A.: Evaluering av måledata for snø, sesongene 2009/2010 og 2010/2011, NVE rapport no. 23, 2011.

Zawadski, I. I.: Statistical properties of precipitation patterns, J. Appl. Meteorol., 12, 459-472, 1973.

\section{HESSD}

8, 11485-11518, 2011

\section{Modelling the spatial} distribution of snow water equivalent

T. Skaugen and

F. Randen

Title Page

Abstract

Introduction

Conclusions

References

Tables

Figures

14

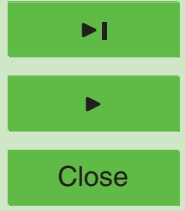

Back

Full Screen / Esc

Printer-friendly Version

Interactive Discussion 


\section{HESSD}

8, 11485-11518, 2011

Table 1. Nash-Sutcliffe values $R^{2}$ for calibration and validation of the HBV model with classical lognormal distribution of SWE (HBV_LN) and with the new gamma distribution for SWE (HBV_G). The parameters of the G_model are estimated from precipitation data.

\begin{tabular}{|c|c|c|c|c|}
\hline Catchment and elevation & HBV_LN & HBV_G & HBV_LN & HBV_G \\
\hline & \multicolumn{2}{|c|}{ Calibration (1961-1981) } & \multicolumn{2}{|c|}{ Validation (1981-2008) } \\
\hline $\begin{array}{l}2.11 \text { Narsjø, } \\
940 \text { m a.s.I. }\end{array}$ & 0.78 & 0.79 & 0.77 & 0.84 \\
\hline $\begin{array}{l}2.32 \text { Atnasjø, } \\
1204 \text { m a.s.I. }\end{array}$ & 0.83 & 0.81 & 0.81 & 0.82 \\
\hline $\begin{array}{l}50.1 \text { Hølen, } \\
1275 \text { m a.s.l. }\end{array}$ & 0.75 & 0.74 & 0.77 & 0.75 \\
\hline $\begin{array}{l}62.10 \text { Myrkdalsvatn, } \\
975 \text { m a.s.l. }\end{array}$ & 0.82 & 0.81 & 0.77 & 0.74 \\
\hline $\begin{array}{l}163.5 \text { Junkerdalselv, } \\
834 \text { m a.s.I. }\end{array}$ & 0.77 & 0.74 & 0.75 & 0.71 \\
\hline
\end{tabular}

\section{Modelling the spatial distribution of snow water equivalent}

T. Skaugen and F. Randen

Title Page

\section{Abstract}

Conclusions

Tables

14

$\triangleleft$

Back
Introduction

References

Figures

$\rightarrow$

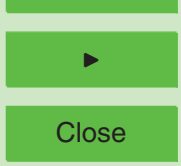

Full Screen / Esc

Printer-friendly Version 


\section{HESSD}

8, 11485-11518, 2011

\section{Modelling the spatial} distribution of snow water equivalent

T. Skaugen and

F. Randen

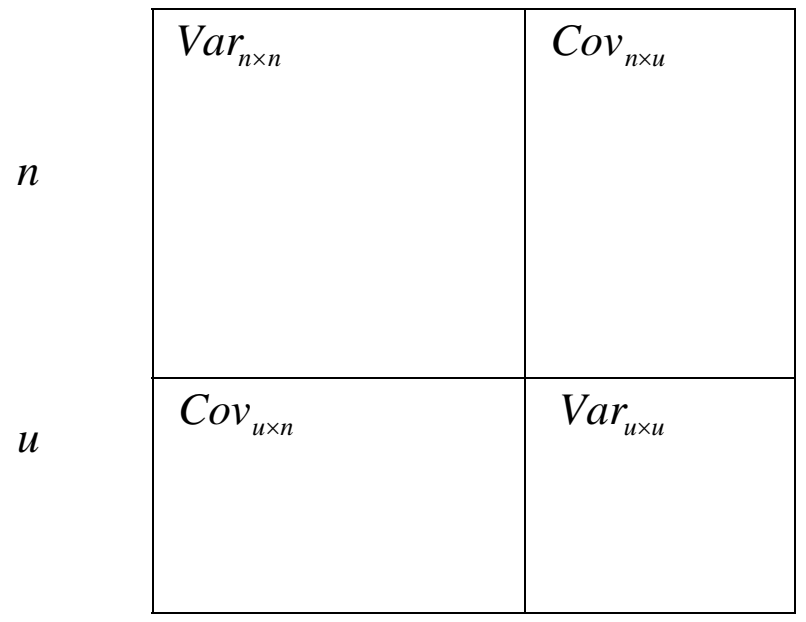

Fig. 1. Covariance matrix for $n+u$ units. Since the matrix is symmetrical, $\operatorname{Cov}_{n \times u}$ and $\operatorname{Cov}_{u \times n}$ are equal.

Title Page

Abstract

Conclusions

Tables

14

4

Back

Full Screen / Esc

Printer-friendly Version

Interactive Discussion 


\section{HESSD}

8, 11485-11518, 2011

\section{Modelling the spatial} distribution of snow water equivalent

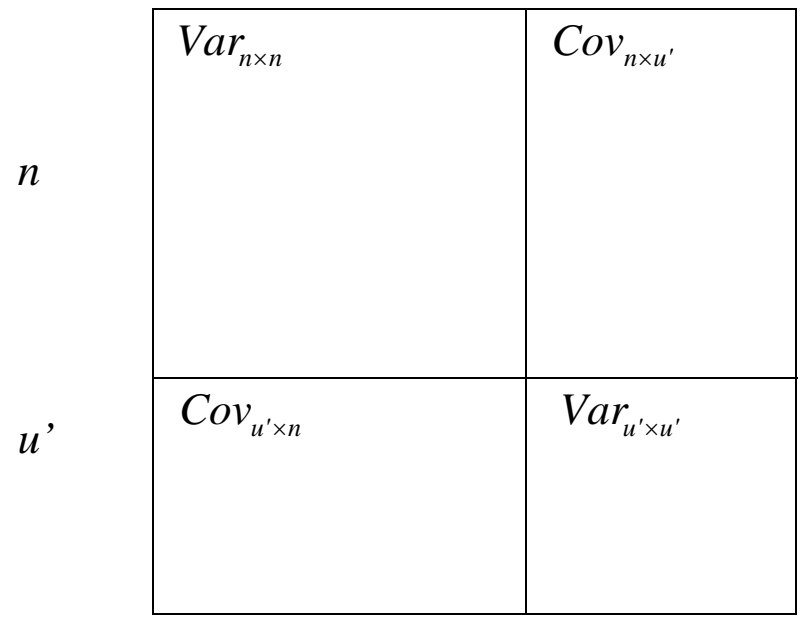

T. Skaugen and

F. Randen

Title Page

\section{Abstract}

Conclusions

Tables

14

4

Back

Full Screen / Esc

Printer-friendly Version

Interactive Discussion 

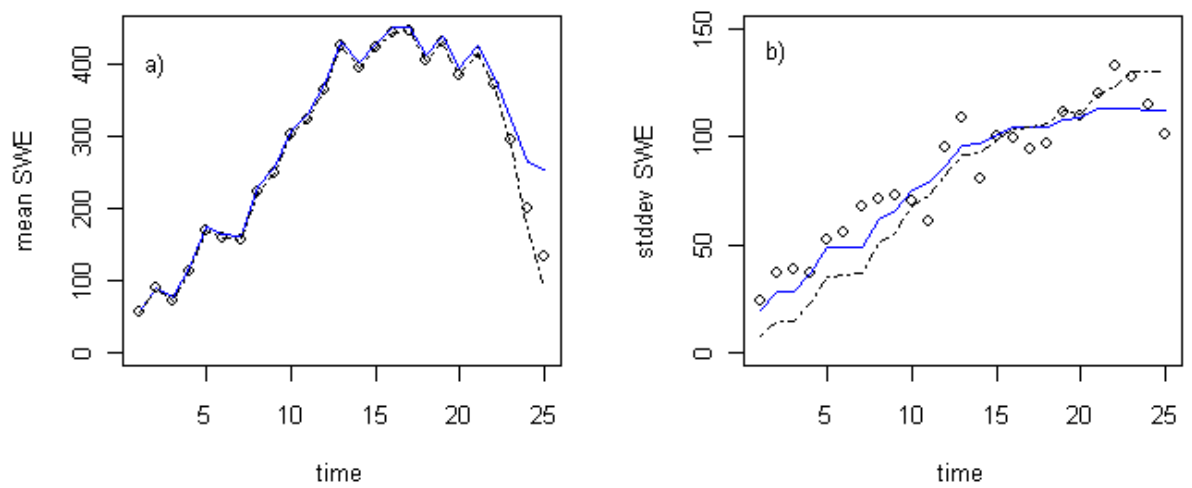

\section{HESSD}

8, 11485-11518, 2011

\section{Modelling the spatial} distribution of snow water equivalent

T. Skaugen and

F. Randen
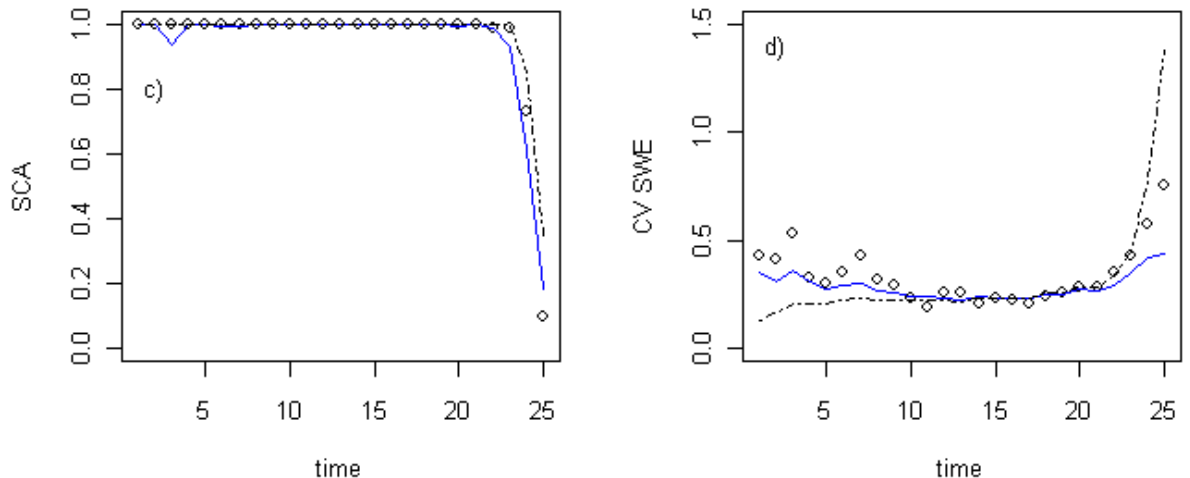

Title Page

Abstract

Introduction

Conclusions

References

Tables

Figures

14

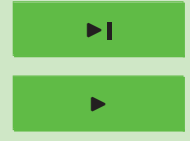

Back

Close

\section{Full Screen / Esc}

Fig. 3. Observed (circles) and simulated with G_model (solid line) and LN_model (dashed line) of conditional mean (a) and -standard deviation (b) and SCA (c) and CV (d) for Norefjell. 

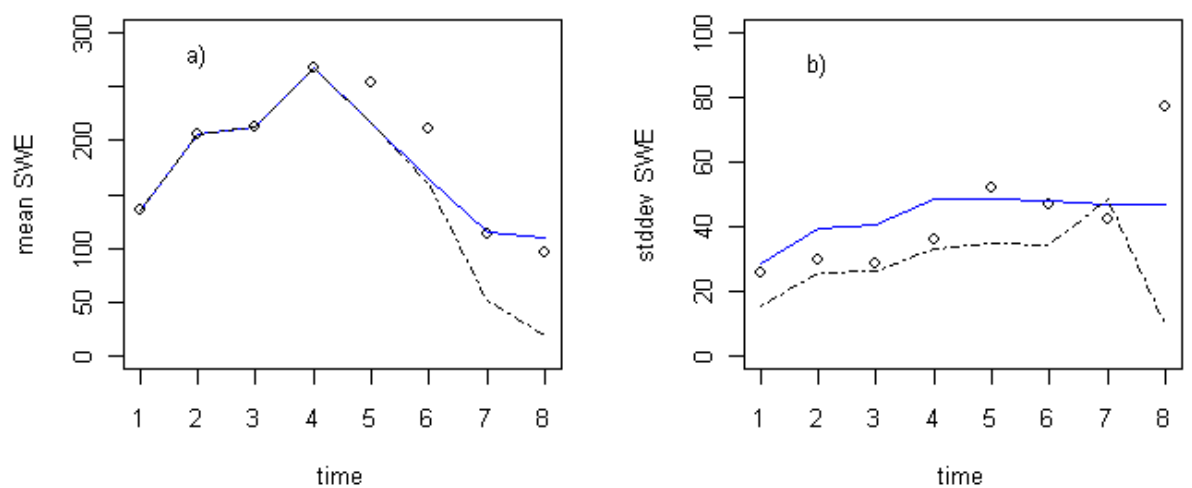

\section{HESSD}

$8,11485-11518,2011$

\section{Modelling the spatial} distribution of snow water equivalent

T. Skaugen and F. Randen
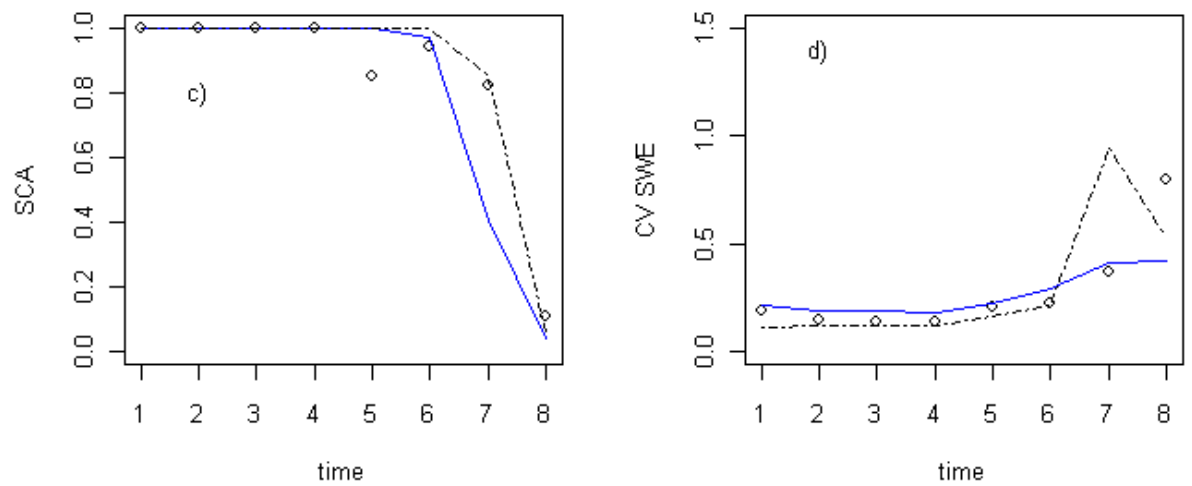

Title Page

Abstract

Introduction

Conclusions

References

Tables

Figures

14

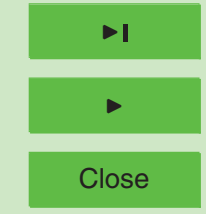

Back

Close

Full Screen / Esc

Fig. 4. Observed (circles) and simulated with G_model (solid line) and LN_model(dashed line) of conditional mean (a) and -standard deviation (b) and SCA (c) and CV (d) for Filefjell.

Printer-friendly Version

Interactive Discussion 

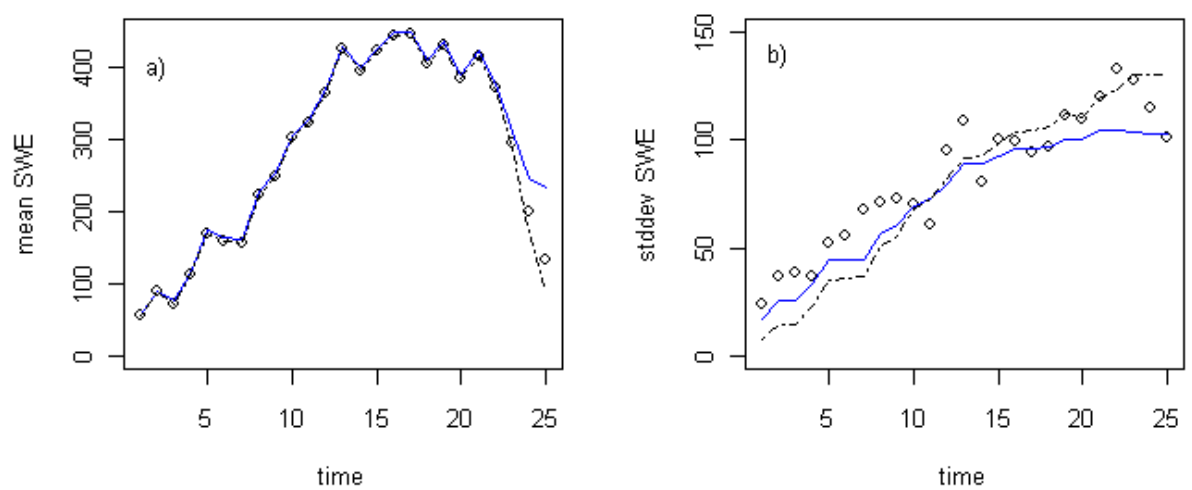

\section{HESSD}

8, 11485-11518, 2011

\section{Modelling the spatial} distribution of snow water equivalent

T. Skaugen and

F. Randen
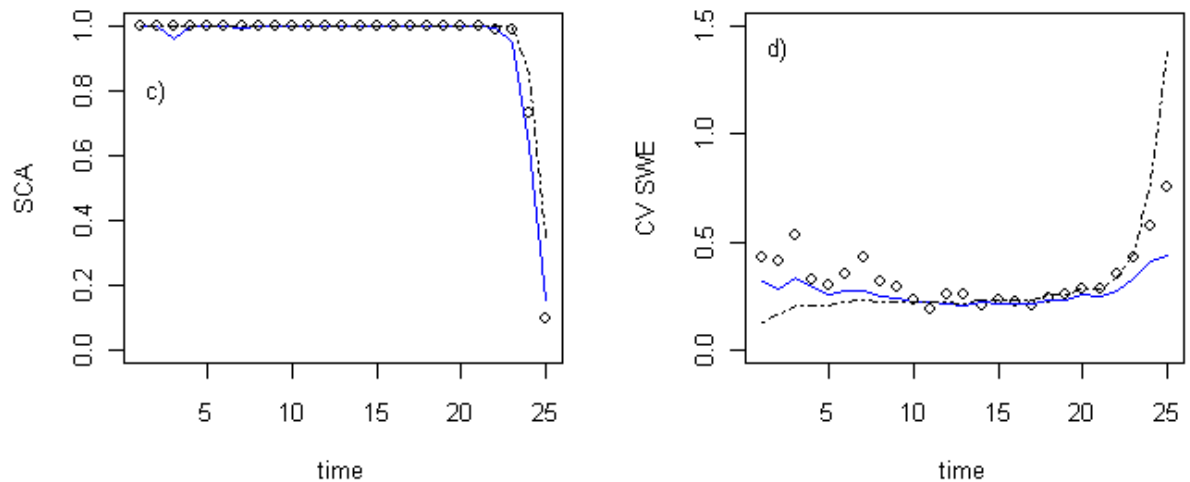

Title Page

Abstract

Introduction

Conclusions

References

Tables

Figures

14

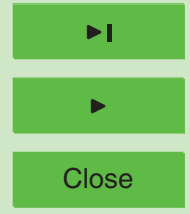

Back

\section{Full Screen / Esc}

Fig. 5. Observed (circles) and simulated with G_model (solid line) and LN_model (dashed line) of conditional mean (a) and -standard deviation (b) and SCA (c) and CV (d) for Norefjell. The parameters of the G_model are estimated from observed precipitation.

Printer-friendly Version

Interactive Discussion 

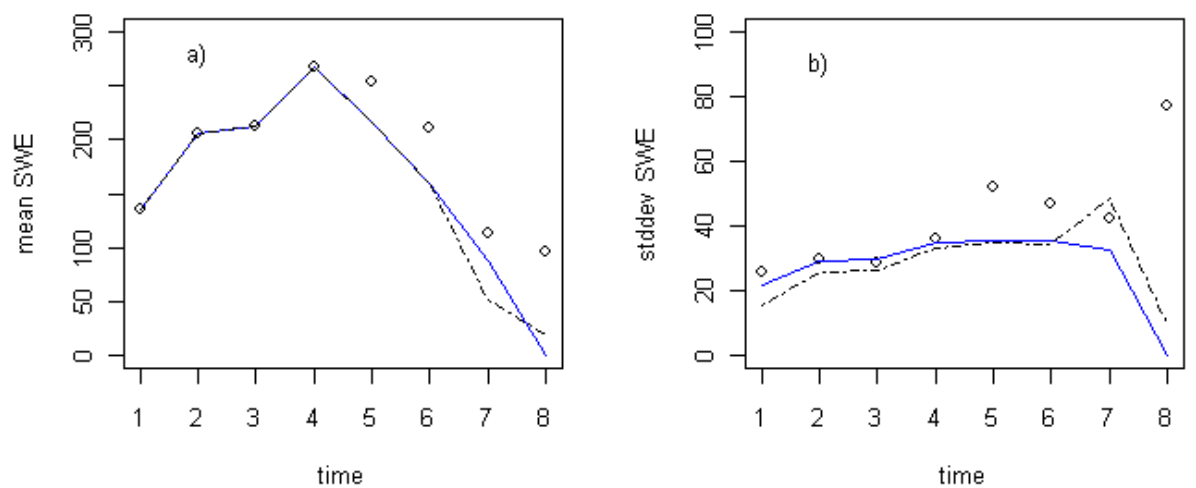

\section{HESSD}

$8,11485-11518,2011$

\section{Modelling the spatial} distribution of snow water equivalent

T. Skaugen and
F. Randen
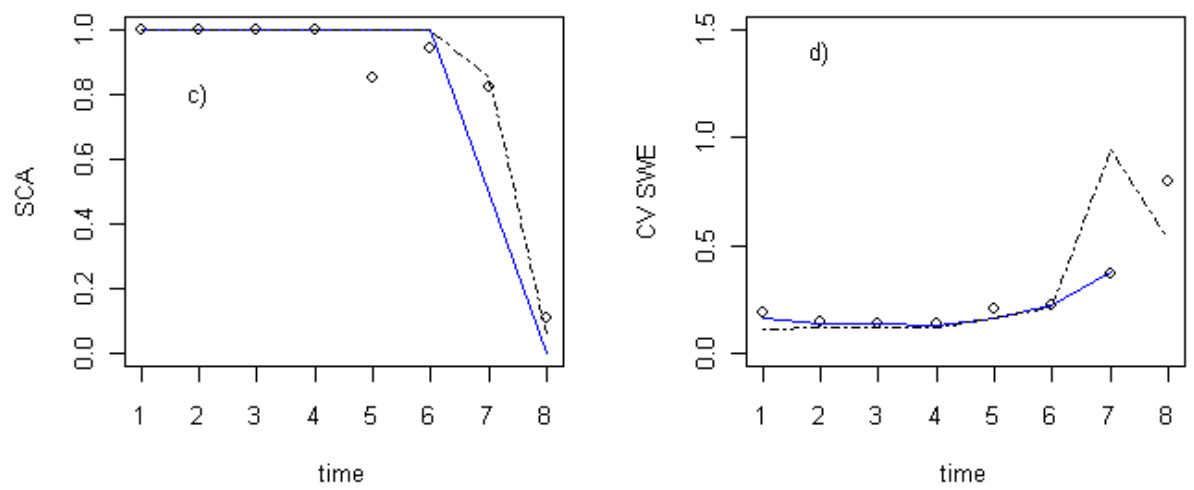

Title Page

Abstract

Introduction

Conclusions

References

Tables

Figures

14

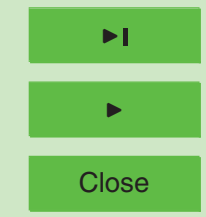

Back

Close

Full Screen / Esc

Fig. 6. Observed (circles) and simulated with G_model (solid line) and LN_model (dashed line) of conditional mean (a) and -standard deviation (b) and SCA (c) and CV (d) for Filefjell. The parameters of the G_model are estimated from observed precipitation.

Printer-friendly Version

Interactive Discussion 


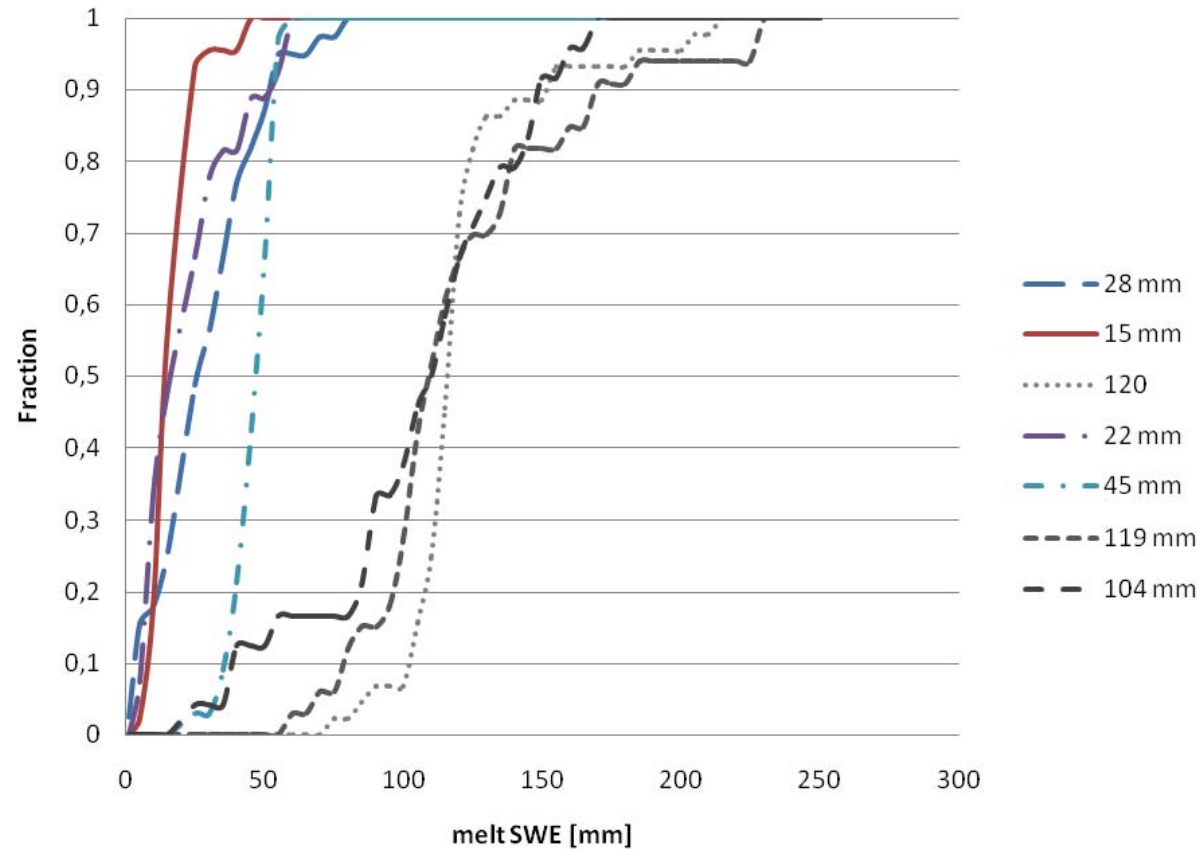

\section{HESSD}

8, 11485-11518, 2011

\section{Modelling the spatial} distribution of snow water equivalent

T. Skaugen and

F. Randen

Title Page

Abstract

Introduction

Conclusions

References

Tables

Figures

14

$>$ I

4

Back

Close

Full Screen / Esc

Printer-friendly Version

Interactive Discussion 


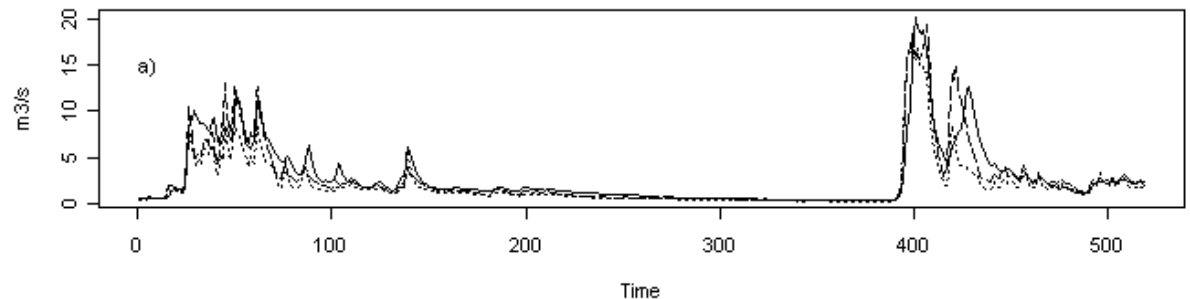

8, 11485-11518, 2011

\section{Modelling the spatial distribution of snow water equivalent}

SWE by HEY_G(solid) and HBV_LN(dotted)

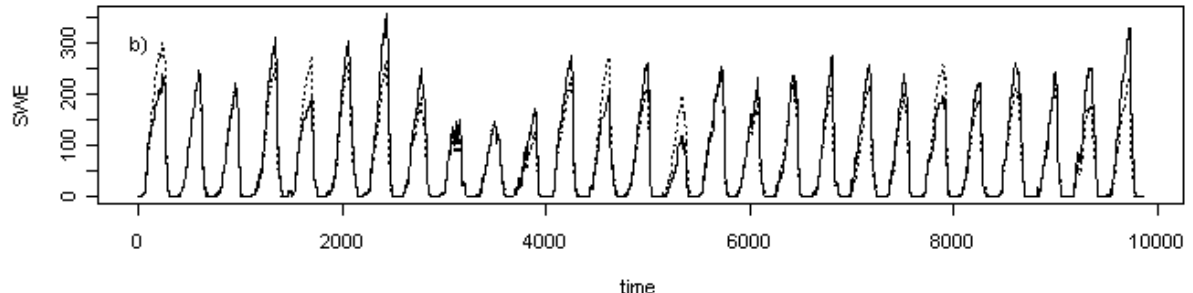

T. Skaugen and

F. Randen

\section{Title Page}

\section{Abstract}

Introduction

Obsewed SCA(MODIS)(black circles), HBV_G(solid) and HBV_LN(dotted)

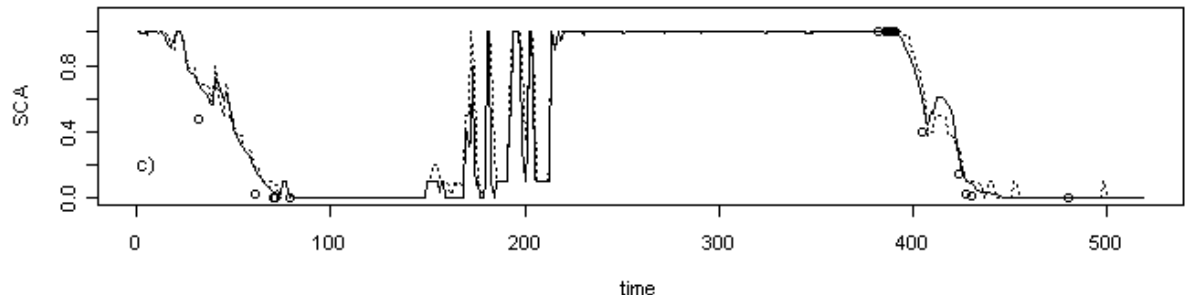

14

4

Back

References

Conclusions

\section{Figures}

Tables

(Figures
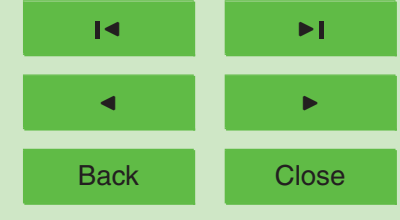

Full Screen / Esc

Printer-friendly Version

Fig. 8. Observed and simulated runoff (a) and SCA (c) and simulated SWE (b) by HBV_LN and HBV_G for the Narsjø catchment. The time period plotted for (a) and (c) is spring 2007-snow season 2008 and for (b) the validation period (1981-2008). 


\section{HESSD}

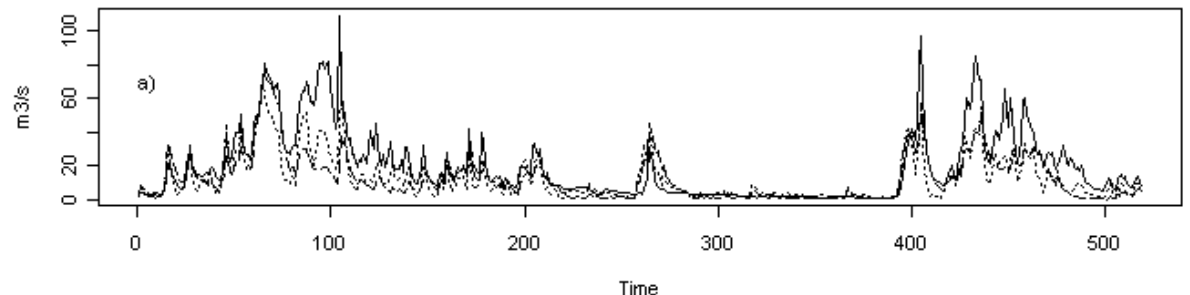

SWE by HBV_G(solid) and HBV_LW(dotted)

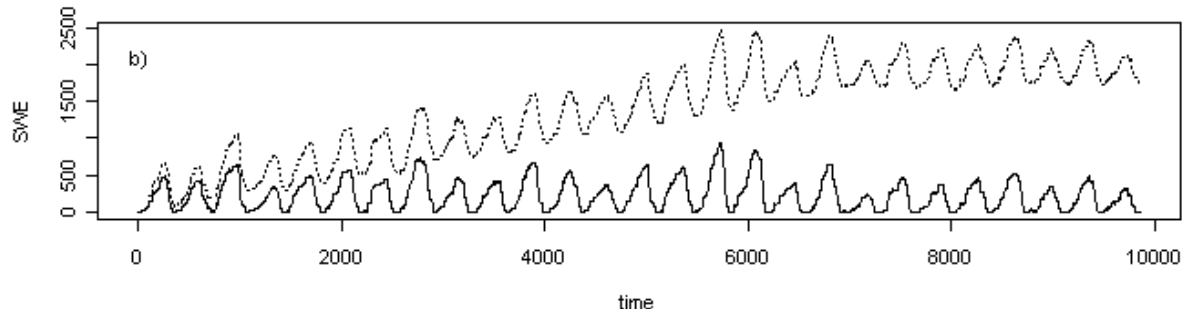

Observed SCA(MODIS)(black circles), HBV_G(solid)and HEV_LW(dotted)

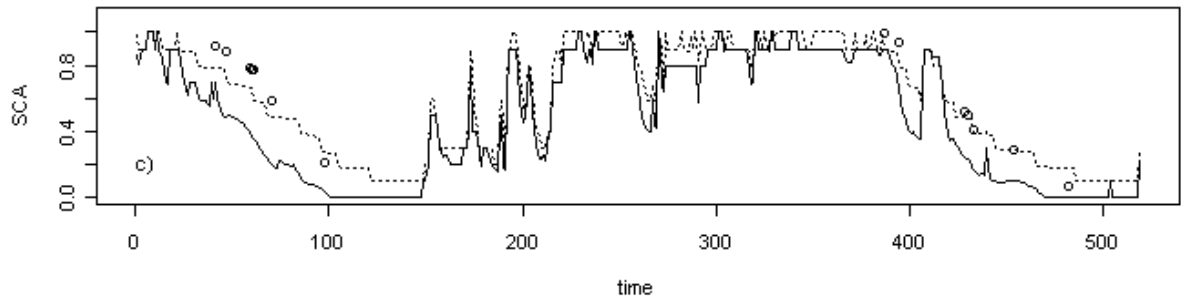

Fig. 9. Observed and simulated runoff (a) and SCA (c) and simulated SWE (b) by HBV_LN and HBV_G for the Junkerdalselv catchment. The time period plotted for (a) and (c) is spring 2007-snow season 2008 and for (b) the validation period (1981-2008).

\section{Modelling the spatial distribution of snow water equivalent}

T. Skaugen and

F. Randen

\section{Title Page}

\section{Abstract}

Introduction

Conclusions

References

Tables

Figures

14

4

Back

Close

\section{Full Screen / Esc}

Printer-friendly Version

Interactive Discussion 